\title{
Accidental poisoning its magnitude and implications in children
}

\author{
Naseem A $A^{1}$, Khurram S. A ${ }^{2}$, Khan S. $S^{3}$, Khan S. K. A $\mathbf{A}^{4}$, Lalani $\mathrm{N}^{5}$ \\ ${ }^{1}$ Dr Altaf Naseem, Associate Professor, ${ }^{2}$ Dr Mir Sumsam Ali Khurram, Associate Professor, ${ }^{3}$ Dr Sana Salim Khan, \\ Senior Resident, ${ }^{4}$ Dr Shafi Khan Ali Khan Gari, Senior Resident, ${ }^{5}$ Dr Nizar Lalani, Dip Child Health, Senior Resident, \\ all are affiliated with Department of Pediatrics, Deccan College of Medical Sciences, Kanchanbag, Hyderabad, India.
}

Address for correspondence: Dr Altaf Naseem, Associate Professor, Department of Pediatrics, Deccan College of Medical Sciences, Kanchanbag, Hyderabad, India. Email: docaltaf@rediffmail.com

\begin{abstract}
Background: Paucity of data due to underreporting of accidental poisoning (AP) poses obstacle in assessing the trend, incidence, and mortality in pediatric population. Objective: Estimating the magnitude and assessing the pattern of AP in children was the primary objective. Describing the affected age group, common agents, and assessment of clinical features were the secondary objectives. Materials \& Methods: Children aged 1month-12years with history of AP were included; those with allergic reactions to plant products, food and idiosyncratic reactions to drugs were excluded. Result: 101 children accounted for $1.7 \%$ of total pediatric admission. Accidental ingestion of poisons (90.09\%) and poisoning due to insect and snake bites $(9.90 \%)$ were reported. Males $(n=62)$ outnumbered females. Patients from urban area $(68.2$ $\%$ ), children aged1-3 years (56.43\%) wereaffected the most. All incidents were unintentional and occured in the home surroundings. April $(n=21)$, March $(n=20)$ recorded higher number followed by December $(n=14)$. Hydrocarbon poisoning (43.56\%) was most common followed by poisoning due to medicaments $(18.8 \%$, ) chemicals $(12.87 \%)$, and food poisoning $(9.90 \%)$. Insect bites \& stings were seen in $9.90 \%$. Supportive treatment was given to $49.5 \%$, further gastric absorption prevented in $24.45 \%$ and specific antidote to $7.9 \%$ patients. Three patients died due to scorpion bite, Phenytoin and kerosene ingestion. Conclusion: AP is a preventable emergency. Incidence, agents, clinical features, treatment administered and therapeutic outcome of AP in children are comparable to the available national data. Preventive measures, strict legislative actions and restriction of availability of hazardous chemicals will reduce the incidence.
\end{abstract}

Key words: Accidental poisoning, Hydrocarbon poisoning, Pediatric population, Unintentional

\section{Introduction}

Poisoning, a common, yet an important preventable cause of morbidity and mortality in children, is a paediatric emergency globally. It's varied clinical profile and therapeutic outcome influenced not only by the prevailing regional social, occupational, economic, and cultural practices, [1] but also by the increased availability of various poisons and associated complexities in its metabolism, adverse effects [2]. Pediatric population is more vulnerable and $47.8 \%$ of poisoning cases are reported in children [3]. Unintentional poisonings are frequent among young children while $50 \%$ poisoning exposure in teenagers are intentional [4-6]. Hospitalization due to accidental poisoning (AP) in children doubled during 1980's

Manuscript received: $25^{\text {th }}$ April 2016

Reviewed: $8^{\text {th }}$ May 2016

Author Corrected; $21^{\text {st }}$ May 2016

Accepted for Publication: $6^{\text {th }}$ June 2016 compared to 1966-70, [7] but recent data is showing declining trend in the incidence and mortality [8-9].

Incidence varies globally depending on the type of poisons encountered, the extent of awareness about poisoning, the availability and access to healthcare facilities. Despite being a global problem, reliable morbidity data is lacking and not comparable among different geographical regions [10]. In southern Brazil, incidence of AP was 339.8 per 100,000 and $58.5 \%$ was due to poisonous substances [11]. Its reported that $56 \%$ of visits to emergency department in 2008 were visits by children $<4$ years due to acute poisoning [12].

In India, while the most pressing and commonest healthissues in childhood still however around infectious diseases and malnutrition, AP is emerging as 
one of the important emergencies encountered in children. Poisoning causes $0.03 \%$ of deaths in infants, $0.16 \%$ in $1-4$ years and $0.37 \%$ in the $5-14$ years age group [13].

Hospital statistics reported periodically from different parts of the country indicate an incidence varying from $0.33 \%-7.64 \%$ of total admissions [14-16].

The incidence of poisoning among pediatric population in India is uncertain as majority of cases are not reported. While the developed countries report low rate of mortality from poisoning (1-2\%), India reports considerably ahigh rate of $5-35 \%$. [5] In spite of successful interventions and safety measures to prevent, toxic exposure continues to be a common occurrence AP in paediatric population. In many countries poisoning is a notifiable condition.

However, this type of reporting is uncommon in India. Despite a fair assumption of the magnitude of the problem, there is a lack of regional data with respect to accidental poisoning in children in our region. Hence, we aimed at defining the epidemiology, clinical profile and outcome of accidental poisoning in children at our tertiary care hospital.

\section{Materials and Methods}

This prospective observational study was undertaken by the department of pediatrics, Deccan College of Medical Sciences, Hyderabad, India. Study material and methodology was reviewed by Institutional ethics committee (IEC).

Study was initiated after obtaining approval from the IEC. Total duration of the study was two years, and IEC monitored the conductance of the study periodically.
Primary objective of our study was to estimate the magnitude and evaluate the pattern (morbidity and mortality) of AP in children. Evaluation of affected age group, common type of poisoning, and assessment of associated clinical features were the secondary objectives.

Written informed consent was obtained from the parents prior to screening. We included all children of 1month-12years, attending Pediatric outpatient and emergency department with history of (h/o)AP and excluded those with allergic reactions to plant products, food and idiosyncratic reactions to drugs.

A pretested, predesigned proforma was used to evaluate the patients. History of ingestion \& type of poison, time taken to reach the hospital, clinical symptoms and signs, treatment offered, therapeutic outcome and complications if any, were noted.

Demographic data was recorded. Involvement of different organs and presenting clinical features were noted. Detailed clinical evaluation was performed.

Treatment provided aimed to stabilize vitals, correct hydration, acidosis, hypoglycemia. Specific measures included decontamination, gastric lavage, administration of activated charcoal and antidotes accordingly to the type and duration of poisoning.

Statistical analysis-Data was captured on Microsoft excel (2010) datasheets, analysed and expressed as mean $\pm \mathrm{SD}$, frequency, percentage, ratio and proportion.

Descriptive analysis was used to describe the results; figures, tables were used to depict and tabulate the results wherever applicable.

\section{Results}

During two years of study period, 101 children were admitted with h/o accidental poisoning, accounting for $1.7 \%$ of total pediatric admission $(\mathrm{n}=5914)$.

Accidental ingestion of poisons $(n=91,90.09 \%)$ and poisoning due to insect \& snake bites $(n=10,9.90 \%)$ were the two reasons for admission. Males $(n=62)$ outnumbered females $(n=39)$ with a ratio of4.77: 3.0 . Two thirds $(n=69, .68 .2 \%)$ of patients were from urban area and $1 / 3 \mathrm{rd}(\mathrm{n}=32,31.68 \%)$ were from rural areas.

Accidental poisoning was seen in $57(56.43 \%)$ children between 1-3 years, followed by poisoning in infants ( $\mathrm{n}=19$, $18.81 \%)($ Fig 1).

All incidents were unintentional, took place in the home surrounding, noticed and brought to hospital by parents. 


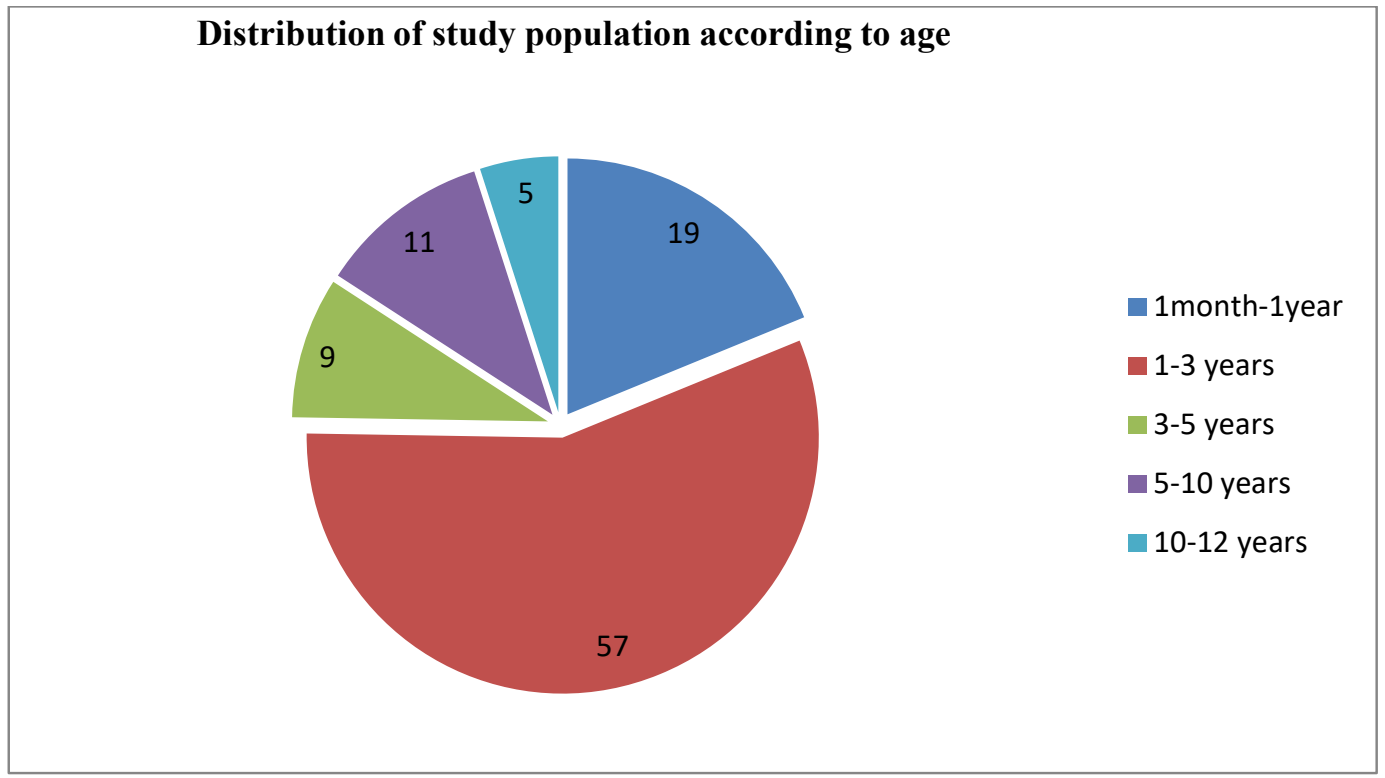

Figure 1: Age wise distribution of study population.

April ( $\mathrm{n}=21)$ and March $(\mathrm{n}=20)$ recorded higher number of admissions followed by December $(\mathrm{n}=14)($ fig 2$)$. There was no significant predominance of any particular time of the day for poisoning; thirty two $(31.68 \%)$ poisoning occurred during morning hours (6 am-12 noon), 36(35.64\%) between 12 noon-6pm and $33(32.67 \%)$ occurred between $6 \mathrm{pm}-6 \mathrm{am}$.

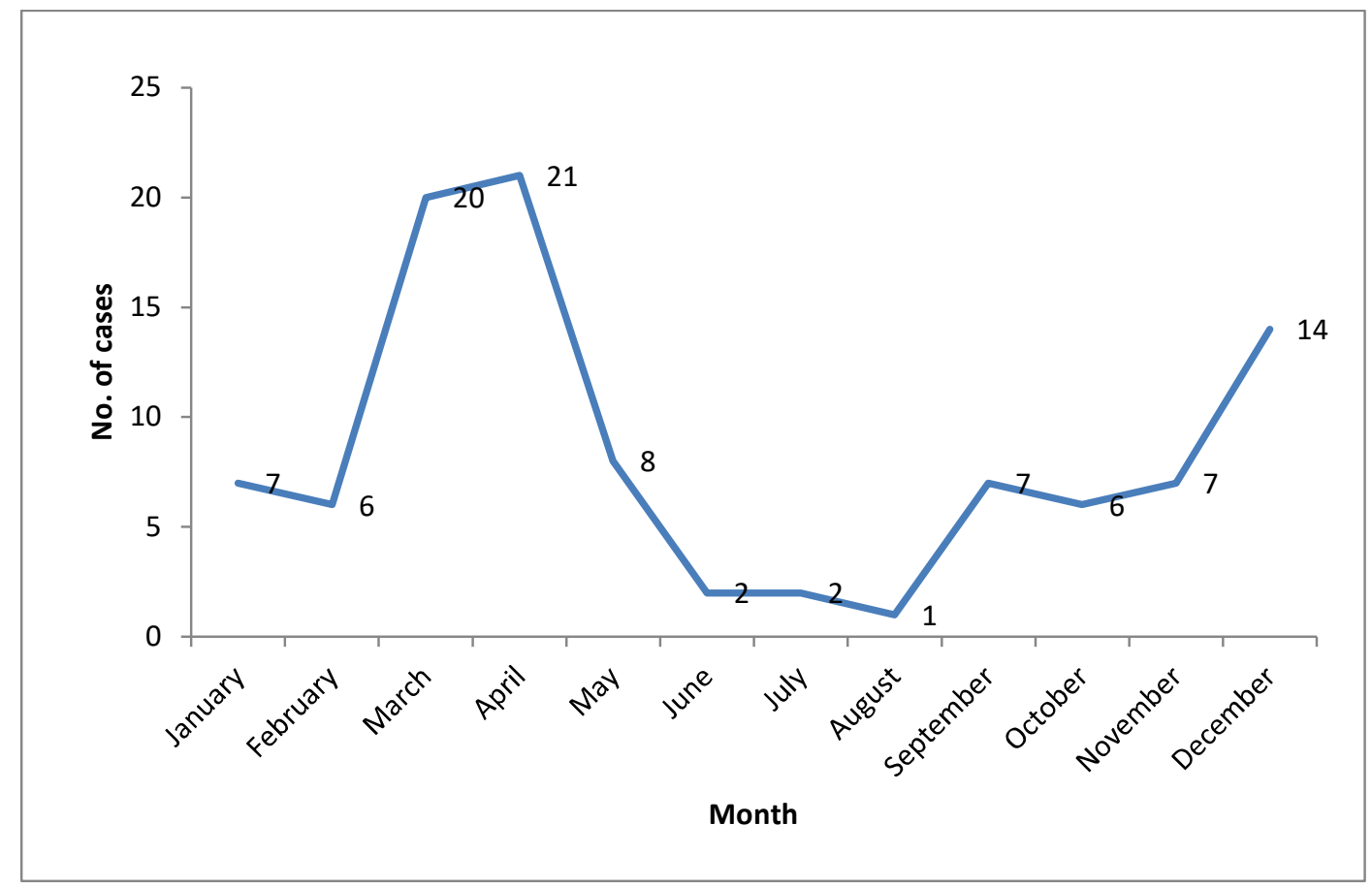

Figure 2: Occurrence of Accidental poisoning in a year.

Hydrocarbon poisoning $(\mathrm{n}=44,43.56 \%)$ namely kerosene was the most common type of poisoning followed by poisoning due to pharmaceutical drugs $(\mathrm{n}=19,18.8 \%)$ (fig 3$)$, chemicals $(\mathrm{n}=13,12.87 \%)$, and food poisoning $(\mathrm{n}=10$, 9.90\%). Insect bites and stings were seen in 10 children (9.90\%); poisoning due to plant products were seen in three children and in two children cause was unknown. 


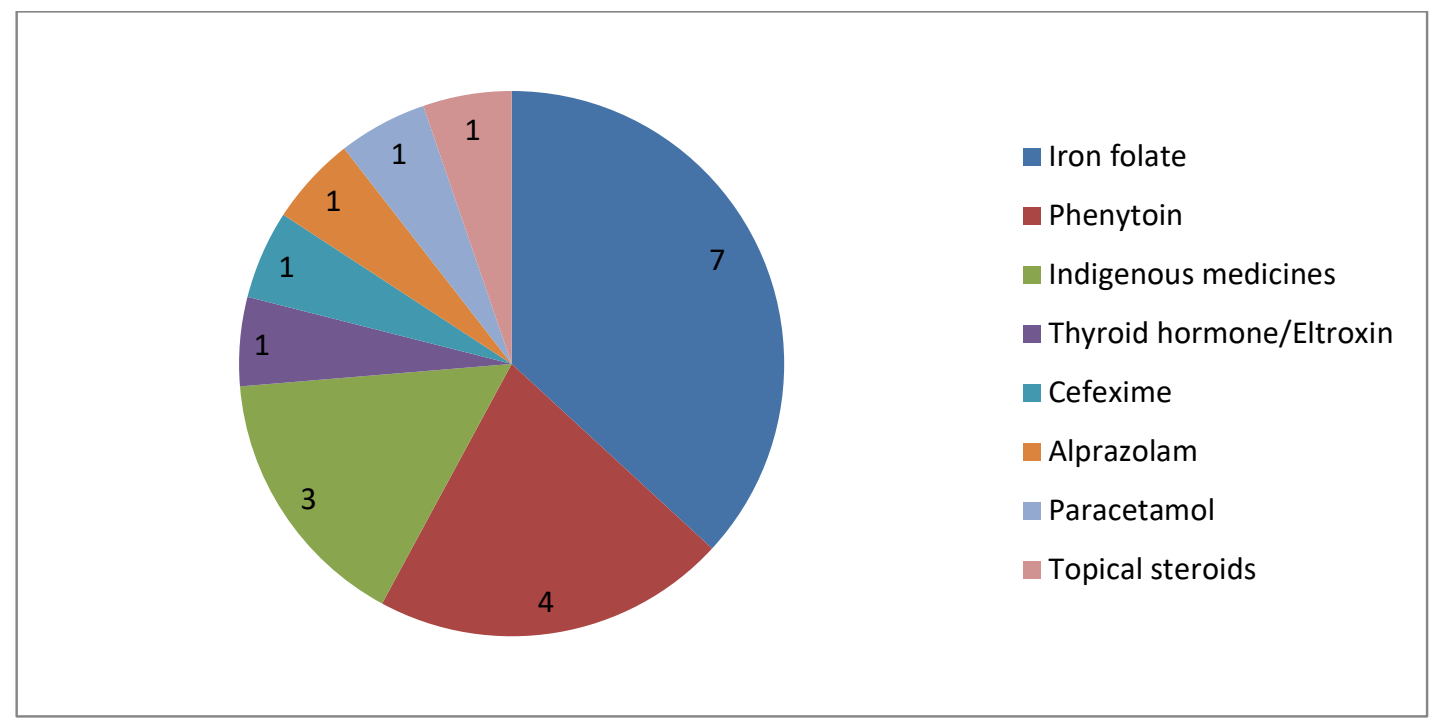

Figure-3: Poisoning due to pharmaceutical agents

Of those who consumed chemicals, ingestion of acid was reported in three patients; poisoning due to ingestion of caustic soda and camphor was seen in two children each and rat poison, fertilizer, pesticides and phenol were the cause in one child each.

Ingestion of castor seeds $(\mathrm{n}=02)$ and datura seeds $(\mathrm{n}=01)$ were reported among ingestion of plant products. Insect bite $(\mathrm{n}=06)$, scorpion and snake bite $(\mathrm{n}=02 \mathrm{each})$ were classified as other poisons. Sixty one cases $(60.39 \%)$ were brought to hospital within 6 hours while 17 (16.83\%) were brought after 6 hours of ingestion (fig 4).

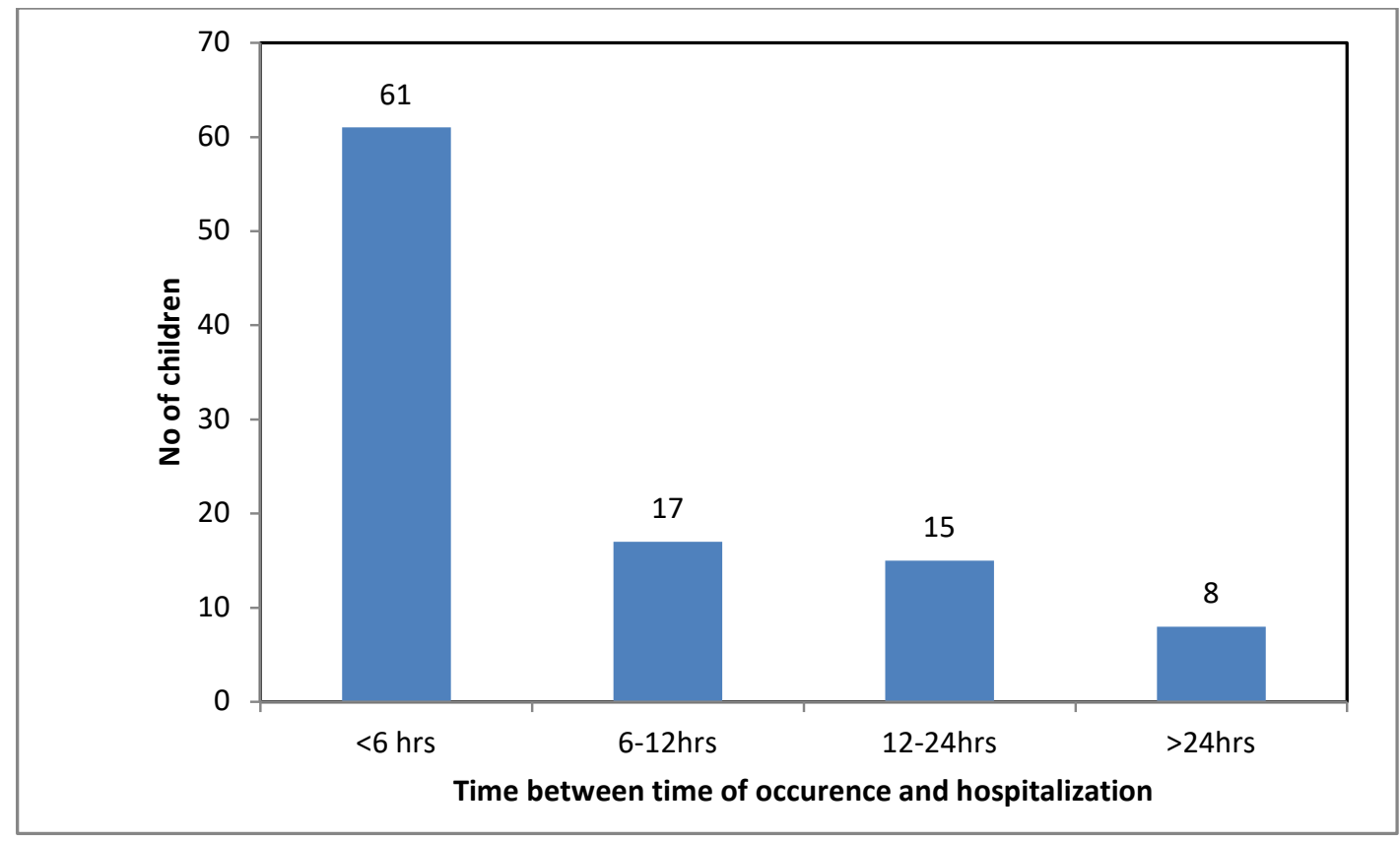

Figure-4: Interval between occurrence of poisoning and hospitalization

Longer hospital stay of $>48$ hours was required in 46 (45.54\%) children while 44 (43.56\%) required 24-48 hrs stay. Only $11(10.89 \%)$ required a shorter stay of $<24$ hours.Of 101 children, $90(89.1 \%)$ were symptomatic; generalized symptoms were seen in $60(66.66 \%)$ (Table 1$)$. 
Table 11: Clinical symptoms reported by the study population.

\begin{tabular}{|c|c|}
\hline Symptoms & Frequency n (\%) \\
\hline General symptoms & $60(66.66)$ \\
\hline Fever & $26(43.3 \%)$ \\
\hline Rash & $13(21.6 \%)$ \\
\hline Pruritis & $07(11.6 \%)$ \\
\hline Abnormal smell & $06(10 \%)$ \\
\hline Sweating & $05(8.3)$ \\
\hline cyanosis & $02(3.3 \%)$ \\
\hline Dehydration & $01(1.6 \%)$ \\
\hline \multicolumn{2}{|l|}{ Systemic } \\
\hline Gastro intestinal & $43(47.7)$ \\
\hline Vomiting & $29(67.4 \%)$ \\
\hline Diarrhea & $06(13.95)$ \\
\hline Abdominal pain & $04(9.3)$ \\
\hline Abdominal distention & $02(4.65)$ \\
\hline Oral ulcers & $02(4.65)$ \\
\hline Respiratory & $27(30)$ \\
\hline Dyspnoea & $13(48.14)$ \\
\hline Cough & $10(37.03)$ \\
\hline Groaning & $04(14.81)$ \\
\hline Central nervous system & $17(18.8)$ \\
\hline Altered sensorium & $09(58.8)$ \\
\hline Seizures & $04(23.52)$ \\
\hline Involuntary movements & $02(11.76)$ \\
\hline Irritability & $02(11.76)$ \\
\hline Cardiovascular & $3(3.3)$ \\
\hline Palpitation & $03(100)$ \\
\hline
\end{tabular}

Supportive treatment i.e., volume replacement, antibiotics, inotropes and antacids to protect the gastric mucosa was given to $50(49.5 \%)$ patients. Prevention of gastric absorption using gastric lavage was done in $24.45 \%$ patients (Table 2 ).

Table 12: Treatment offered to the study population.

\begin{tabular}{|l|l|}
\hline Treatment & Frequency (\%) \\
\hline Observation & $10(9.9 \%)$ \\
\hline Prevention of gastric absorption (Gastric lavage) & $25(24.45 \%)$ \\
\hline Supportive (I.V. fluids, antibiotics, inotropes, antacids) & $50(49.5 \%)$ \\
\hline Specific antidote & $8(7.9 \%)$ \\
\hline $\begin{array}{l}\text { Treatment received elsewhere, } \\
\text { before admission }\end{array}$ & $8(7.9 \%)$ \\
\hline
\end{tabular}

Three patients $(2.97 \%)$ died in this study within 24 hours of admission, one each due to scorpion bite, Phenytoin and kerosene ingestion. Cause of death was shock in scorpion bite, arrhythmia in phenytoin poisoning and severe pneumonia and respiratory failure in kerosene poisoning. 
Subgroup analysis: Hydrocarbon poisoning: Poisoning due to ingestion of kerosene was reported among this poisoning. Of 44 patients, $33(75 \%)$ were symptomatic; respiratory $(n=16,48.48)$, central nervous system (CNS) $(n=10,30.3 \%)$ and gastrointestinal $(\mathrm{n}=7,21.21 \%)$ systems were involved.

Dyspnea was the commonest symptom in $13(29.55 \%)$ patients followed by altered sensorium in eight (18.18\%). Crepitations in 13 (29.55\%) patients followed by tachypnea in11 (25\%) patients were the frequent signs.

Of 44, Positive radiological findings were seen in 21 patients. Presence of unilateral or bilateral lower lobe infiltrates $(n=9,42.85 \%)$, followed by infiltrates seen throughout the lung fields $(n=4,19.04 \%)$ were frequent radiological findings.

Table 3 summarises the features seen in those with hydrocarbon poisoning.

Table-13: Characteristics of Kerosene poisoning.

\begin{tabular}{|l|l|}
\hline Parameters & Frequency (\%) \\
\hline Symptoms & \\
\hline Dyspnoea & $13(29.55)$ \\
\hline Altered sensorium & $08(18.18)$ \\
\hline Cough & $08(18.18)$ \\
\hline Vomiting & $08(18.18)$ \\
\hline Seizures & $04(9.09)$ \\
\hline Fever & $03(6.81)$ \\
\hline Signs & \\
\hline Crepitations & $13(29.55)$ \\
\hline Tachypnoea & $11(25.00)$ \\
\hline Wheeze & $07(15.91)$ \\
\hline Chest retractions & $05(11.36)$ \\
\hline Groaning & $03(6.82)$ \\
\hline Tachycardia & $03(6.82)$ \\
\hline Cyanosis & $02(4.55)$ \\
\hline Radiological findings & \\
\hline Unilateral/bilateral lower lobe infiltrates & $09(42.85)$ \\
\hline Diffuse infiltrate & $04(19.04)$ \\
\hline Unilateral/bilateral upper lobe infiltrate & $03(14.28)$ \\
\hline Perihilar infiltrate & $03(14.28)$ \\
\hline Lobar consolidation & $02(09.52 \%)$ \\
\hline
\end{tabular}

\section{Discussion}

Availability of many complex chemicals, immaturity of organs to handle the toxin load, smaller body size which makes the toxin load heavy, contribute to the consequences of accidental poisoning. In addition, physiology of children makes AP a complex clinical entity particularly in pediatric population [10]. Available reports state poisoning as accidental in children admitted with $\mathrm{h} / \mathrm{o}$ poisoning $[3,12,17-20]$. In our study, AP accounted for $1.7 \%$ pediatric admissions in accordance with observation of GhoshVB et al. [21] Kouéta $\mathrm{F}$ et al [22] noted rate of hospitalization for acute AP as $1.3 \%$.
Accidental poisoning in pediatric age group is commonly seen in $<5$ yrs $[3,18,21-22]$ and more frequent among 1-3 years group. [3,11, 19]. In our study too, children aged 1-3 yr were affected the most $(56.43 \%)$, followed by infants $(18.81 \%)$. This is comparable with global trend and in accordance with the available national data. Home surrounding has been reported as most frequent place of occurrence [17] and our study is in support of this. Thisis because of restricted locomotion in this population. Accidental poisoning in pediatric age group is unintentional in 10$90 \%$ population. [3, 17-18] Our study group had 
restricted the upper range to 12 years, and all cases were unintentional. All children were noticed and brought to hospital for treatment by parents. Homicidal poisoning in this age group is rare and there was no homicidal or suicidal poisoning reported in our study, similar to the study by Ghosh VB et al. [21]

Male predominance is reported by various studies. [3, 7, 18-22] and our study supports this observation with male : female ratio of $4.77: 3.0$. Female predominance was seen in very few studies.[23]

We observed that $2 / 3^{\text {rd }}(68.2 \%)$ of our patients were from urban area and only 1/3rd (31.68\%) were from rural areas. Ours being a tertiary care centre, located in the urban area, might have resulted in this observation. Moreover, most of the primary health care centres are equipped with manpower with required expertise and are capable of handling non fatal cases, resulting in referral of less number.

Number of hospital admission due to AP were higher during summer, in April $(n=21)$ and March $(n=20)$ followed by December $(n=14)$. Global studies too noted higher number of incidence in April. [22] This could be attributed to the school vacation during this period.

There is a global variation in the pattern of poisoning agents consumed; it is fuels (paraffin, kerosene), pharmaceuticals, cleaning agents in developing countries while, over the counter (OTC) medications, household products (cleaning agents), pesticides, plant products, insect and animal bites are the causative agents in developed countries. [10] There is no significant change in this order of occurrence whichremained the same since 6-7 decades. Pharmaceutical compounds were the most frequent poisoning agent [24], followed by household agents [18], other chemicals and venomous plants. [7,17] Household products were listed the leading cause followed by traditional medicines, bites from venomous insects and snake bite by Kasilo et al; surprisingly, pharmaceutical products were last in the list. [3] In our study, poisoning by fuel (Hydrocarbon 43.56\%) namely kerosene was frequent followed by pharmaceutical drugs (18.8\%), chemicals (12.87\%), and food poisoning $(n=10,9.90 \%)$. It is in agreement with Unicef statement on poisoning agents. Kouéta $\mathrm{F}$ et al [22] noted household product in the top of the list of causative agent, followed by medicinal agents and food. Poisoning due to Kerosene was seen in $54.5 \%$ patients in their study. In our study, kerosene poisoning was seen in slightly lesser percentage $(43.56 \%)$ and food poisoning was seen in $9.90 \%$ patients.

Developed countries have recorded pharmaceutical agents as the highest cause of AP in children, OTC medications being most frequent. Kouéta $\mathrm{F}$ et al [22] reported poisoning due to tranqullizers (46.4\%) was most frequent. Antihistaminics and benzodiazepines were the most frequent cause in a study by Pearn $\mathrm{J}$ et al. [8] We noted iron-folate $(6.93 \%)$ as the leading cause in this category, followed by phenytoin (3.96\%) and indigenous agents $(2.97 \%)$. Iron folate being prescribed routinely to the expecting and lactating mothers could have resulted in easy access to these medications by the children. Phenytoin is the common antiepileptic agent prescribed to children and adults which could be the reason attributable to this finding. Indigenous medications are generally preferred by the general public with a notion that they are without side effects and stored for future re use.

Household agents such cleansers tops the listof chemicals, globally. Our study too supports this fact as there was report of ingestion of acid $(n=03)$; caustic soda and camphor ( $\mathrm{n}=02$ each) were other agents consumed. There was ingestion of rat poison, fertilizer, pesticides and phenol but only in minority of study population. The percentage was less due to increased awareness among parents who kept them at secured place.

Other poisoning due to insect, scorpion and snake bite was reported in $9.90 \%$ of study population. There is global variation due to geographical characteristics. Poisoning due to caterpillars, bees and spiders were reported from south Brazil [11]. In our study cause of poisoning remained unknown in two children.

Interval between time of consumption of poisoning and medical intervention is crucial to minimize further damage and complications. In our study, 60.39\%) were brought to hospital within 6 hours which resulted in positive therapeutic outcome as reaching the hospital early resulted in initiation of appropriate therapy early.

In our study, longer hospital stay of $>48$ hours was required in $45.54 \%$ children while $43.56 \%$ required 24 48 hrs of stay. Only $10.89 \%$ required short stay of $<1$ day. Global statistics about duration stay varies from $<$ 1 day to $>14$ days. Hospitalization of $<2$ days was frequent. [7] Studies have documented the mean stay as 2 days. [23]. 
As hydrocarbon poisoning ( $\mathrm{n}=44,43.56 \%$ ) was seen in many, we did a sub analysis. Of these patients, 75\% were symptomatic, Respiratory symptoms (48.48\%) and those related to CNS $(30.3 \%)$ were predominant while gastrointestinal symptoms were seen only in $21.21 \%$. Dyspnea $(\mathrm{n}=13,29.55 \%)$ and altered sensorium $(\mathrm{n}=8,18.18 \%)$ were common symptoms in this subgroup. Clinically, crepitations $(n=13,29.62 \%)$ and tachypnea $(n=11,25 \%)$ were noted. Positive radiological findings on chest X-ray were noted in $47.73 \%$ patients; presence of unilateral or bilateral lower lobe infiltrates $(42.85 \%)$, followed by infiltrates seen throughout the lung fields $(19.04 \%)$ were frequent radiological findings. Inhalation while ingestion is common which resulted in development of respiratory symptoms, clinical signs and radiological findings on chest X-ray.

Poisoning due to kerosene constituted $1.2 \%$ of all pediatric admission in previous study. Age group $<2$ years was most affected with peak incidence in 1.5 years. Cough and dyspnoea were the common symptoms, involvement of CNS was also reported. [25] Unlike our study, this study reported three deaths in this category.

There has been decrease in mortality rate among children with accidental poisoning. Available data on mortality varies from $0-3 \%$. [18,22] Mortality under 1 year has been reported to be very high due to acute poisoning while in 1-4 year age group it is considered to be non fatal.High mortality rate of $7.7 \%$ was noted by Ghosh VB et al. [21] In our study, three patients $(2.97 \%)$ died due to scorpion bite, overdose of phenytoin and ingestion of kerosene.

Various Indian studies have documented incidence of poisoning among children varying between 0.3 to $7.6 \%$. [13-14] Accidental poisoning occurred in 1.1\% -3.9\% of pediatric admissions, most frequent between 0-5 years with male predominance. Poisoning was more frequent in summer. Kerosene was the most frequently used agent followed by medicines, [26-27] though the trend is showing a decline. [20] Similar clinical and radiological description of kerosene poisoning in children was noted in our study population. Our data is similar to that obtained by our neighboring country. [19] indicating geographical, socioeconomical, educational similarities. Pharmaceutical products topped the list in Pakistan, whereas we observed poisoning with hydrocarbon (kerosene). Clinical features and treatment offered were in similar lines. We did not have patients who were discharged against medical advice as reported by Abbas et al. [19] Gontko $\mathrm{K}$ et al noted slight deviation from the existing data. Poisoning in girls was more frequent. Mean age was higher with 10 yrs. Medicinal agents $(46.75 \%)$ were the most common cause; poisoning byethyl alcohol (24.35\%), carbon monoxide (17.86\%) and chemicals (11.04\%) were noted. In contrast to our study, poisoning occurred during October, December and September. Intentional poisoning was recorded in $50.69 \%$ children. Interestingly, they noted consumption of mixture of medicines and with ethyl alcohol. Among chemicals, detergents were the most frequently ingested. [28]

Our study had few limitations. The data available from the present study does not enable the assessment of risk factors. However, by identifying the importance of childhood poisoning as a cause of morbidity as well as the relative importance of different poisoning agents may channel the intervention programs and further research in the right direction. Assessment of relation of socioeconomic circumstances, psychological state of parents and the child would have been more appropriate.

There has been a strong recommendation to enhance the awareness among general public regarding accidental poisoning in children. [29] Recommending increased awareness through mass media and community outreach as preventive measures, [22] proper storage of medicinal products and chemicals, strict legislature directing to adopt child safety measures in the packing of these and proper enforcement of these rules and regulations [17]. We insist on mandatory reporting by the practicing physicians and pediatricians to the national registry. We recommend adopting better safety measures such as use of child resistant containers for medications, keeping the hazardous substance out of reach for children, not leaving the children unattended, administration of medications under supervision. Reaching the hospital within the golden hour, availability of life saving drugs, including antidotes helps in reducing the morbidity and mortality. Flow charts for emergency management and necessary facilities and medicines should be made available at all health centres so that treatment may be promptly instituted. Contribution of Mass media in enhancing the public awareness through advertising the preventive measures and common immediate first aid measures will help to reduce the incidence and complications of AP. 


\section{Conclusion}

Accidental poisoning, a preventable emergency is still a concern in pediatric practice. Though there is a declining trend, complexity of chemicals and associated complications result in fatal reactions. Incidence, agents used for poisoning, clinical features, treatment admninistered and therapeutic outcome are comparable to the available national data. Preventive measures such as increased awareness among parents, storing the medicines and chemicals in child resistant containers, out of reach of children, availing treatment at the earliest will contribute to the reduction of incidence. Strict legislator measures are required for the packing of pharmaceutical and chemical agents in child resistant containers and restriction of availability of hazardous chemicals.

Acknowledgement: We acknowledge the children who participated in this study. We thank the staff of pediatric emergency and out patient department who assisted in the conduct of the study. We thank the hospital management who supported this study. We thank Dr M S Latha for her assistance in the preparation, editing and proof reaing.

\section{Funding: Nil, Conflict of interest: Nil \\ Permission from IRB: Yes}

\section{References}

1. Bhatkumar N, Dhar M, Ahmad S, Chandar V. Profile of poisoning in children and adolescents at a North Indian tertiary care centre. JIACM 2011; 13:37-42.

2. Martin TC, Brinkman W. The spectrum of accidental childhood poisoning in the Caribbean. Rev Panam Salud Publica. 2002 Nov;12(5):313-6

3. Kasilo OM, Nhachi CF. A pattern of acute poisoning in children in urban Zimbabwe: ten years experience. Hum Exp Toxicol. 1992 Sep;11(5):335-40.

4. Bronstein AC, Spyker DA, Cantilena LR Jr, Green JL, Rumack BH, Giffin SL. 2009 Annual Report of the American Association of Poison Control Centers National Poison Data System (NPDS): 27th Annual Report. ClinToxicol (Phila). 2010 Dec; 48(10):9791178. doi: 10.3109/15563650.2010.543906.

5. Pillay VV. MKR Krishna's Hand book of Forensic Medicine and Toxicology. 12th Ed. Paras Publication. Hyderabad: 276-299, 2001.
6. Budhathoki S1, Poudel P, Shah D, Bhatta NK, Dutta AK, Shah GS, et al. Clinical profile and outcome of children presenting with poisoning or intoxication:a hospital based study. Nepal Med Coll J. 2009 Sep; 11(3):170-5.

7. Sommerfelt $\mathrm{K}$, Vogt $\mathrm{H}$. Accidental poisoning in children. Tidsskr Nor Laegeforen. 1990 Aug 10;110 (18):2345-8. [Abstract, article in Norwegian].

8. Pearn J, Nixon J, Ansford A, Corcoran A. Accidental poisoning in childhood: five year urban population study with 15 year analysis of fatality. Br Med J (Clin Res Ed). 1984 Jan 7;288(6410):44-6.

9. Chowdhury FR, Rahman AU, Mohammed FR, Chowdhury A, Ahasan HA, Bakar MA. Acute poisoning in southern part of Bangladesh-the case load is decreasing. Bangladesh Med Res Counc Bull. 2011 Aug;37(2):61-5.

10. No author listed]. Children and poisoning.Unicef. WHO.Available from http://www.who.int/violence injury_prevention/child/injury/world_report/Poisoning english.pdf. accessed on 26 May 2016.

11. Martins CB, de Andrade SM, de Paiva PA. Accidental poisoning among children and adolescents in a county in southern Brazil. Cad Saude Publica. 2006 Feb; 22(2):407-14. [Abstract, article in Portuguese].

12. NalliahRP, Anderson IM, Lee MK, Rampa S, Allareddy V, Allareddy V. Children in the United States make close to 200,000 emergency department visits due to poisoning each year. Pediatr Emerg Care. 2014 Jul;30 (7): 453-7. doi: 10.1097/ PEC. 0000000000000 160 .

13. Satpathy R, Das BB. Accidental poisoning in childhood.J Indian Med Assoc.1979Dec1;73(11):190-2.

14. Buhariwalla RJ, Sanjanwalla..Poisoning in children: A study of 303 cases.Indian Pediatr. 1969 Mar; 6 (3):141-5.

15. Agarwal V, Gupta A. Accidental poisoning in children. Indian Pediatr. 1974 Sep;11(9):617-21.

16. Buch NA, Ahmed K, Sethi AS. Poisoning in children. Indian Pediatr. 1991 May; 28(5):521-4. 
17. Azkunaga B, Mintegi S, Salmón N, Acedo Y, Del Arco L; Grupo de Trabajo de Intoxicaciones de la Sociedad Española de Urgencias de Pediatría. Poisoning in children under age 7 in Spain. Areas of improvement in the prevention and treatment. AnPediatr (Barc). 2013 Jun; 78 (6):355-60. doi: 10.1016/j. anpedi. 2012.09.016. [Abstract, article in Spanish].

18. Mucci N, Alessi M, Binetti R, Magliocchi MG. Profile of acute poisoning in Italy. Analysis of the data reported by Poison Centres. Ann Ist Super Sanita. 2006;42(3):268-76.

19. Abbas SK, Tikmani SS, Siddiqui NT. Accidental poisoning in children. J Pak Med Assoc. 2012 Apr; 62(4):331-4.

20. Jayashree M, Singhi S. Changing trends and predictors of outcome in patients with acute poisoning admitted to the intensive care. J Trop Pediatr. 2011 Oct;57(5):340-6. doi: 10.1093/tropej/fmq099

21. BrataGhosh V1, Jhamb U, Singhal R, Krishnan R. Common childhood poisonings and their outcome in a tertiary care center in Delhi.Indian J Pediatr. 2013 Jun;80(6):516-8. doi: 10.1007/s12098-012-0879-5.

22. Kouéta F, Dao L, Yé D, Fayama Z, Sawadogo A. Acute accidental poisoning in children: aspects of their epidemiology, aetiology, and outcome at the Charles de Gaulle Paediatric Hospital in Ouagadougou (Burkina Faso). Sante. 2009 Apr-Jun;19(2):55-9. doi: 10.1684/ san. 2009.0157.
23. Margonato FB, Thomson Z, Paoliello MM. Acute intentional and accidental poisoning with medications in a southern Brazilian city. Cad SaudePublica. 2009 Apr; 25(4):849-56.

24. Sever M, Saz EU, Koşargelir M. An evaluation of the pediatric medico-legal admissions to a tertiary hospital emergency department. Ulus Travma Acil Cerrahi Derg. 2010 May;16(3):260-7. [Abstract, article in Turkish]

25. Belonwu RO, Adeleke SI. A seven-year review of accidental kerosene poisoning in children atAminu Kano Teaching Hospital, Kano. Niger J Med. 2008 OctDec; 17(4):380-2.

26. Khadgawat $\mathrm{R}$, Garg $\mathrm{P}$, Bansal $\mathrm{P}$, Arya A, Choudhary B.Accidental poisoning.Indian Pediatr. 1994 Dec; 31(12):1555-7.

27. Singh A, Choudhary SR. Accidental poisoning in childrenIndian Pediatr. 1996 Jan;33(1):39-41.

28. Gontko K, MitkowskaJ ,Panienski P, Ratajczak K. Acute poisonings in children in the years 2010-2012single-centre study in Poznań. PrzeglLek. 2013; 70 (8) : 533-7. [Abstract, article in Polish]

29. BeikircherM ,Berenzi P, Mantovan F. Prevention of accidental poisonings in the household with children under 6 years of age. Kinderkrankenschwester. 2012 May; 31(5):190-3. [Abstract, article in German]

\section{How to cite this article?}

Naseem A, Khurram S. A, Khan S. S, Khan S. K. A, Lalani N. Accidental poisoning its magnitude and implications in children. Int J Pediatr Res.2016;3(6):400-409.doi:10.17511/ijpr.2016.i06.06. 